\title{
HISTÓRIAS DE JOAQUINAS: \\ MULHERES, ESCRAVIDÃO E LIBERDADE \\ (BRASIL, AMAZONAS: SÉC. XIX)
}

Ygor Olinto Rocha Cavalcante

Patrícia Melo Sampaio

oaquina nasceu em tempos revolucionários. Os anos de 1830 no Grão-Pará viram eclodir uma das principais revoluções sociais ocorridas na parte norte do Império: a Cabanagem. Este extraordinário movimento popular aglutinou homens e mulheres de múltiplos estratos sociais e étnicos e ampliou-se por todo o vale amazônico colocando em evidência diferentes projetos sociais. Escravos fugidos, quilombolas, indígenas, desertores, gente de toda sorte vivendo nas camadas mais empobrecidas da sociedade paraense encontrariam na Cabanagem formas de luta contra a opressão, "aprendendo a amar a aclamação popular e a revolução infinita”, como afirmou Magda Ricci. ${ }^{1}$

\footnotetext{
Mestrando do Programa de Pós-Graduação em História da Universidade Federal do Amazonas.

** Professora do Departamento de História da Universidade Federal do Amazonas.

1 Para Magda Ricci a Cabanagem foi um movimento revolucionário de ampla participação social, abrangendo as elites antiportuguesas, as populações indígenas, comunidades de escravos fugidos, quilombolas e soldados desertores, cujas lutas em comum se assentavam no ódio ao mandonismo branco e português - especialmente aqueles mais abastados. Ao longo do movimento, a participação destes sujeitos foi mediada (e transformada) por conflitos de classes e interesses políticos e -econômicos. Depois que as elites revoltosas tomaram o poder e colocaram a província em estado de guerra civil, não houve como refrear tal movimento, disso resultando um profundo espraiamento da revolução por outras classes nos mais remotos lugares da província e áreas de fronteira internacional. A par do nascimento de outros chefes
} 
Este tempo de instabilidade e morte foi o que viu nascer Joaquina. A memória de sua primeira infância deve ter sido marcada por certo temor causado pelas guerrilhas nos rios e igarapés, pelas emboscadas e ataques imprevisíveis dos cabanos no momento de dispersão do movimento. Pouco sabemos de sua vida até os 18 anos. Contudo, é certo que a menina Joaquina fazia parte da terceira ou quarta geração de escravos de origem africana vivendo em terras amazônicas. Desde finais do século XVII, homens e mulheres embarcados em África atravessaram o Atlântico para trabalhar, em geral, nas atividades agrícolas, nos serviços urbanos e nas atividades ligadas à extração dos produtos da floresta.

Ao longo do século XVII e início do século XVIII, a incipiente rota de tráfico de escravos para o estado do Maranhão e Grão-Pará esteve assentada em três motivos básicos: as epidemias de varíola que dizimaram os trabalhadores indígenas em finais do Seiscentos; a estratégia da Fazenda Real de utilizar o comércio de africanos para dinamizar a reprodução do domínio militar na região; e, como resultado das leis de liberdade indígena na década de 1680, a atuação da Companhia de Comércio do Maranhão. Nesse contexto, os "suspiros por um escravo de Angola" tornavam-se lamentações generalizadas pelo braço africano na sociedade colonial em formação. Este desejo, inclusive, era constantemente alimentado pela experiência bem sucedida do tráfico negreiro para o Estado do Brasil, cujos colonos e comerciantes engrossavam mais e mais os seus cabedais com o trabalho dos africanos. O papel da Coroa portuguesa foi vital neste processo e possuía dois objetivos: estabelecer uma conexão

cabanos, a luta por direitos e liberdades surgia em cada vila ou aldeia da Amazônia desconsiderando qualquer tipo de autoridade e hierarquias sociais instituídas. Ver: Magda Ricci, "Cabanagem, cidadania e identidade revolucionária: o problema do patriotismo na Amazônia entre 1835 e 1840", Tempo, v. 11, n. 22 (2007), pp. 15-40; José Murilo de Carvalho considera a luta dos cabanos como a mais sangrenta da historia do Brasil: mais de $30 \mathrm{mil}$ mortos e um crescimento populacional que só na década de 1860 ganharia vigor. Verificar: José Murilo de Carvalho, Cidadania no Brasil. O longo caminho, Rio de Janeiro: Civilização Brasileira, 2002, p. 69. Em outro artigo Magda Ricci critica a interpretação corrente na historiografia que entende a Cabanagem apenas como uma revolta ou rebelião separatista, isto é, uma tensão típica do período regencial: Magda Ricci, "Fronteiras da nação e da revolução: identidades locais e a experiência de ser brasileiro na Amazônia (1820-1840), Boletín Americanista, ano LVIII, n. 58 (2008), pp. 77-95. Para uma análise mais demorada sobre historiografia da Cabanagem, ver também: Luís Balkar Pinheiro, Visões da Cabanagem uma revolta popular e suas representações na historiografia, Manaus: Editora Valer, 2001. 
atlântica dinamizando a economia colonial no Maranhão e Pará, "calando os murmúrios" por escravos decorrentes dos problemas quanto à escravização dos índios, e solidificar sua presença em África. ${ }^{2}$

Este quadro sofre sensível modificação quando das ações administrativas do Marquês de Pombal na segunda meado do XVIII. As chamadas "reformas pombalinas" intensificaram a entrada de africanos no Grão Pará e Maranhão e estabeleceram redes de abastecimento e escoamento dos produtos das lavouras da região, tais como o arroz, o algodão, e dos produtos da floresta (cacau, salsaparrilha, cravo, entre outros).

A presença sistemática de africanos surtiu efeitos concretos para a realidade social da Amazônia. Fortaleceu as atividades econômicas da região, com o incremento da produção agrícola e, sobretudo, consolidou os grupos de proprietários de terra que, obviamente, traduziram esse poderio econômico em força política. Desta maneira, homens e mulheres embarcados em diferentes portos africanos formaram as escravarias de senhores paraenses e maranhenses até o inicio do século XIX e atuaram em atividades diversas, tais como lavouras de cacau, agricultura, pecuária e nas atividades domésticas. ${ }^{3} \mathrm{Na}$ região do Baixo Amazonas, foi possível, por exemplo, o desenvolvimento de uma produção açucareira, com "engenhos e engenhocas", sustentada com mãode-obra africana, constituindo-se em uma realidade econômica importante até a primeira metade do século XIX. ${ }^{4}$

\footnotetext{
Manolo Florentino \& João Fragoso, O arcaísmo como projeto. Mercado Atlântico, sociedade agrária e elite mercantil em uma economia colonial tardia, Rio de Janeiro, c. 1790-c. 1840, Rio de Janeiro: Civilização Brasileira, 2001. Ver também: Rafael Chambouleyron, "Suspiros por um escravo de Angola. Discursos sobre a mão-de-obra africana na Amazônia seiscentista", Humanitas, v. 20, n. 1/2 (2004), pp. 99-111; Rafael Chambouleyron, "Escravos do Atlântico equatorial: tráfico negreiro para o Estado do Maranhão e Pará (século XVII e início do século XVIII)", Revista Brasileira de História. v. 26, n. 52 (2006), pp. 79-114; Reinaldo Barroso Junior, "Nas rotas do atlântico equatorial: tráfico de escravos rizicultores da Alta-Guiné para o Maranhão (1770-1800)" (Dissertação de Mestrado, Universidade Federal da Bahia, 2009).

3 Vindos, inicialmente, da região da Alta-Guiné, logo outros portos alimentariam o tráfico equatorial: Guiné, Angola, Malagueta, Costa da Mina e Moçambique. Ver: Maria Celeste G. Silva, "Dimensões atlânticas: notas sobre o tráfico negreiro e as rotas comerciais entre a Alta Guiné e o Maranhão, 1755-1800", Anais do XIX Encontro Regional de Historia: Poder, Violência e Exclusão. ANPUH/SP-USP. São Paulo, 2008. Cd-ROM.

4 Ver Flávio dos Santos Gomes, A hidra e os pântanos: mocambos, quilombos e comunidades de fugitivos no Brasil (séculos XVII-XIX), São Paulo: Ed. UNESP/POLIS, 2005, p. 44. Sobre as atividades em que a mão-de-obra africana foi empregada no baixo Amazonas, ver também: Eurípedes Funes, "Nasci nas matas, nunca tive senhor": história e memória dos mocambos do
} 
Joaquina descende diretamente destes homens e mulheres africanos, cuja exploração da força de trabalho permitiu aos seus proprietários angariar poder econômico e político que estiveram na base dos conflitos que culminaram na eclosão do movimento cabano. A bem da verdade, exploração, exclusão e acumulação de riquezas estavam no berço de Joaquina. Ainda pequena começou a participar do trabalho cotidiano das escravas do Grão-Pará e Rio Negro. Trabalhando como lavadeira, cozinheira, engomadeira, vendedeira, circulou pelas ruas e igarapés de uma cidade que tentava se reorganizar no período pós-Cabanagem. Acompanhou a criação da província do Amazonas, em 1852, e as modificações urbanas pelas quais passava a sua capital, Manaus, vivendo em um prédio residencial e comercial localizado na Rua Brasileira: a casa de seu senhor.

\section{Ser escravo no Amazonas: trabalho, desigualdades e hierarquias sociais no século XIX}

Joaquina era escrava de Antônio Lopes Braga, que era membro de uma família de comerciantes e militares, com uma bem sucedida carreira pública e atuação na política local. Já em 1852, quando da instalação da província, era contador escrivão da Fazenda. Quatro anos depois, assumiria o cargo de juiz municipal e de órfãos de Manaus, acumulando-o com a presidência da câmara municipal. Em 1860, o jornal Estrella do Amazonas o considerava um dos mais importantes dentre os "cidadãos com condições para o bom desempenho do mandato popular". Em 1869, Braga era líder do partido conservador e, depois do sucesso das eleições, o Jornal do Commércio assegurava que o "capitão Braguinha" gozava de "verdadeira influência popular no Amazonas". Se a carreira de homem público era reconhecida, os negócios também prosperavam; desde 1854, era sócio de seu irmão Hermenegildo Lopes Braga formando a firma Lopes Braga \& Irmão. ${ }^{5}$

baixo Amazonas, in João José Reis e Flávio dos Santos Gomes (orgs.), Liberdade por um fio: história dos quilombos no Brasil, São Paulo: Companhia das Letras, 1996, p. 470.

5 Governo do Amazonas. Auto da Installação da Província do Amazonas pelo Exmo. Snr. João Baptista de Figueiredo Tenreiro Aranha, seu $1^{\circ}$ Presidente, no dia $1^{\circ}$ de janeiro de 1852 . Manaus: Typographia de M. da S. Ramos, 1852. Acervo do Centro de Documentação e Apoio à Pesquisa (CENDAP/PPGSCA/UFAM) - Jornal Estrella do Amazonas, 4 de março de 1854; 18 de maio 
Os estudos sobre as hierarquias sociais e fortunas em Manaus permitem dimensionar o lugar dos escravos nessa sociedade. O acesso à mão-de-obra escrava era privilégio de poucos. Este fato ganha maior dimensão se levarmos em consideração que a realidade social da província era de acentuada pobreza com opções limitadas de investimento e fortes restrições de capitais. De acordo com os dados dos inventários post-mortem, a maioria dos inventariados $(60,5 \%)$ não possuía escravos. Por outro lado, mais de $80 \%$ dos cativos registrados nos inventários, no final da década de 1860 , estava nas mãos de menos da metade dos proprietários. ${ }^{6}$

Na década de 1840, a grande maioria dos proprietários de escravos estava ligada ao setor da agricultura (68\%). Os agricultores também controlavam parte significativa das fortunas inventariadas $(44,8 \%)$. Na década de 1850, esta composição sofre uma mudança significativa quando os setores ligados ao comércio passam a controlar não só a maioria dos escravos $(39,5 \%)$, como também da maior parte da riqueza produzida $(64,6 \%)$. Este movimento de maior controle de escravos e fortunas se incrementa nas décadas posteriores e se altera apenas na década de 1880 , quando os setores ligados às atividades extrativas - proprietários de seringais - passaram a controlar mais de $56 \%$ dos escravos.

Antônio Lopes Braga fazia parte então de um seleto grupo de comerciantes que, desde a década de 1850, ligados ao capital mercantil, engrossavam os seus cabedais, investindo em prédios urbanos, comércio e posse de escravos. Braga transformou em renda política todas estas posses no conjunto de uma sociedade profundamente desigual e hierarquizada. $^{7}$

de 1854; 20 de outubro de 1858; 15 de agosto de 1860 e Jornal do Commércio, 4 de fevereiro de 1869. Sobre a presidência da Câmara, cf. Livro de Atas da Câmara Municipal de Manaus (1858-1864). Arquivo Legislativo da Câmara Municipal de Manaus.

6 Cf Patrícia M. Sampaio, "Nas teias da fortuna: acumulação mercantil e escravidão em Manaus, século XIX”. Mneme - Revista de Humanidades, Caicó, v. 3, n.6 (2002).

7 A noção de renda política está em Manolo Florentino e José Roberto Góes e pretende dar conta do processo de constituição social de um tipo especifico de trabalhador pacificado: o escravo. Segundo os autores, "este processo iniciava-o o mercado, pela introdução do estrangeiro, e concluía-o o próprio escravo, tornado africano e brasileiro, membro de uma comunidade, de um nós cativo". O controle da escravaria, e de sua produtividade, dependeriam da criação e recriação de parentesco, assegurando ao senhor a própria capacidade de retornar ao mercado. Nesse sentido, a forma como 
Compartilhando as mesmas condições jurídicas de Joaquina, existiam no Amazonas, de acordo com o censo de 1872, 979 indivíduos. Números relativos à população da província, abarcando, praticamente, todo o século XIX, revelam certa estabilidade desta população variando algo em torno de mil escravos. Vivendo em Manaus na década de 1870, Antônio Lopes Braga fazia parte de uma população branca estimada em 2.899 pessoas. A maior parte dos habitantes da capital foi classificada como "caboclos" (12.084 indivíduos), categoria censitária utilizada para enquadrar as populações indígenas que viviam em espaço urbano e que compunham a maioria dos trabalhadores da região. Outros homens e mulheres de cor (pretos e pardos) de Manaus somavam 2.603 pessoas e nem todas eram livres: 377 deles eram escravas. ${ }^{8}$

Estamos diante de uma cidade multiétnica, majoritariamente habitada por indígenas, seguida de brancos, mas com um importante contingente de população de cor. Nesse universo diverso e desigual, a possibilidade de ser proprietário de outrem se constituía como um relevante indicador de status social, considerando a natureza da escravidão na província. Nesta direção é importante notar que a província do Amazonas possuía o segundo maior percentual de escravos vivendo em espaço urbano de todo o Império (50,9\%). Somente o Rio de Janeiro possuía percentual maior de cativos vivendo em ambiente urbano (76,5\%). ${ }^{9}$

Não há como negar a importância da presença de Joaquina na vida material e social do Amazonas. Circulando pela cidade e desempenhando suas atividades no comércio, nos serviços domésticos e outros mais, Joaquina era imediatamente identificada como propriedade de Braga, reiterando a imagem de seu senhor como homem de posses. É bem provável que Joaquina tenha conquistado, junto a ele, autonomia

nos apropriamos do conceito não difere substancialmente do proposto pelos autores, mas procura sublinhar a posse de escravos como elemento chave na reiteração de um status social diferenciado no conjunto das disputas pelo poder na sociedade amazonense oitocentista. Ver: Manolo Florentino \& José Roberto Góes, A paz das senzalas: famílias escravas e tráfico atlântico, Rio de Janeiro, c. 1790-c.1850, Rio de Janeiro: Civilização Brasileira, 1997, p. 37.

8 Ver Patrícia M. Sampaio, Os fios de Ariadne: tipologias de fortunas e hierarquias sociais em Manaus: 1840-1880, Manaus: EDUA, 1997.

9 Renato L. Marcondes, "Desigualdades regionais brasileiras: comércio marítimo e posse de cativos na década de 1870" (Tese de Livre Docência, Universidade de São Paulo, 2005), p. 87. 
suficiente para juntar seus trocados e formar um pecúlio. Afinal, concessões e violências podem ser faces da mesma dominação. ${ }^{10}$

Além do caráter multiétnico da cidade de Manaus, é preciso chamar atenção para outro processo em curso: as modificações no seu espaço urbano. Desde a década de 1840 a cidade passava por um conjunto de transformações caudatárias da maior circulação de bens e mercadorias que se dirigiam para a praça de Belém. Na segunda metade do século XIX, Manaus já era rota de passagem obrigatória de gêneros e produtos para o Pará e constituía-se como entreposto comercial estratégico subordinado, apenas, à praça de Belém. A circulação de trabalhadores e mercadorias se intensificava. Marinheiros de pequenos vapores e navios, remeiros, canoeiros, regatões, cozinheiros de embarcações, oficiais de calafate, pedreiros, carpinteiros e carregadores se misturavam às lavadeiras, cozinheiras, engomadeiras, vendedeiras, sapateiros, ferreiros, lavradores, jornaleiros e outros que passavam a integrar a paisagem social da cidade.

Este quadro aparentemente estável da dinâmica urbana era abalado com as fugas constantes dos índios recrutados nas diferentes localidades da província. Estas deserções, não só das obras públicas como dos serviços militares, aparecem com certa regularidade nos jornais publicados no XIX e na documentação policial. A falta de trabalhadores qualificados somada às frequentes deserções alimentavam as reclamações relativas à "escassez de mão-de-obra". Digamos de outro modo: a demanda dos "distintos cavalheiros" da província por trabalhadores era insaciável. ${ }^{11}$

${ }^{10}$ Silvia Lara, operando com a noção de reciprocidade formulada por Edward Thompson, argumenta que o senhores de escravos até podiam considerar os seus cativos como seres despossuídos de vontade própria, impondo-lhes um comportamento passivo e subordinado. Mas da contradição resultante desta impossibilidade de os escravos tornarem-se acéfalos e anômicos (ou seja, mera extensão da vontade de seus senhores) surge a política do paternalismo, isto é, as ideias e projetos pelos quais os escravos lutavam (e conquistavam) eram tratadas como generosas concessões. Por outro lado, os escravos traduziam essas "concessões" em direitos que deveriam ser mantidos. Sob esta perspectiva analítica, compreende-se as relações senhor-escravo permeada de "direitos e deveres" que deveriam ser recíprocos. Ver: Silvia Hunold Lara, “'Blowin in the Wind': Thompson e a experiência negra no Brasil”, Projeto História, n.12 (1995), pp.43-56.

11 Parte dos jornais referidos integram acervo do CENDAP/PPGSCA. Outros títulos também foram pesquisados em mais duas instituições: Centro Cultural Povos da Amazônia e Instituto Histórico e Geográfico do Amazonas - IGHA. Os livros da Secretaria de Polícia foram digitalizados do Arquivo Público do Estado do Amazonas e cópias digitais integram acervo do Núcleo de Pesquisa em Política, Instituições e Práticas Sociais (POLIS). Quanto ao recrutamento de índios e a atuação das 
Em 1854, o Ministério dos Negócios do Império, interessado em incentivar a construção de uma nova olaria em Manaus, e para minimizar as dificuldades de braços, enviou para o Amazonas seis africanos livres que deveriam ser colocados à disposição do novo empreendimento. Até 1866, este número subiria para 57 africanos livres, segundo estimativas de Gustavo Ramos Ferreira, vice-presidente da província. Estes trabalhadores desempenhariam atividades fundamentais para o governo provincial. Segundo o presidente Manoel Clementino da Cunha, mesmo não sendo "operários da melhor qualidade", os africanos supriam as crescentes demandas provinciais. Assim, atuariam no serviço da limpeza da casa destinada para funcionar o Educandos Artífices, nas obras do cemitério São José, nas obras da nova igreja matriz, na retirada de pedras para a construção dos prédios públicos, na reforma da enfermaria militar e no palácio da presidência. ${ }^{12}$

Joaquina certamente esbarrou com estes africanos enquanto desempenhava suas tarefas ou simplesmente vagava pela cidade. Eles costumavam sair do bairro Costa d'África onde residiam, atravessavam toda a cidade, passando quase que obrigatoriamente pela rua Brasileira para ficar as "noites nos riachos desse estabelecimento [Educandos

diretorias de índios no século XIX, ver Patrícia M. Sampaio. "Política indigenista no Brasil Imperial", in Keila Grinberg \& Ricardo Salles (orgs.), O Brasil imperial (1808-1889) (Rio de Janeiro: Civilização Brasileira, 2008), v. 1, pp. 175-206.

12 Estrella do Amazonas, 4 de maio de 1854. Governo da Província do Amazonas. Relatório com que o Exmo. Sr. $1^{o}$ Vice-Presidente da Província do Amazonas abriu a Assembleia Legislativa provincial, no dia 05 de setembro de 1866. Africanos livres configuram um grupo particular de homens e mulheres que faziam parte dos carregamentos das embarcações capturadas no tráfico ilegal e, deste modo, não eram considerados escravos. Eram colocados sob a tutela do Estado e/ou de particulares por prazo determinado até que pudessem ser emancipados. Para uma discussão mais completa, ver Beatriz Mamigonian, "Revisitando a "transição para o trabalho livre': a experiência dos africanos livres", in Manolo Florentino, Trafico, cativeiro e liberdade: Rio de Janeiro, séculos XVII-XIX (Rio de Janeiro: Civilização Brasileira, 2005), pp. 389-417. Sobre a presença de africanos livres no Amazonas, ver Patrícia M. Sampaio, "Escravidão e liberdade na Amazônia: notas de pesquisa sobre o mundo do trabalho indígena e africano", Anais do III Encontro Escravidão e Liberdade no Brasil Meridional [recurso eletrônico], 2005. Também cf: Governo da província do Amazonas. Relatório apresentado á Assembleia Legislativa do Amazonas pelo Exmo. Senr. Dr. Manoel Clementino Carneiro da Cunha Presidente da mesma Província na Sessão ordinária de 3 de maio de 1862, Manaus: Typographia de F. C. Rhossard, 1862, p. 20. As informações sobre as atividades dos africanos livres estão no Estrella do Amazonas, 24 de março de 1858; 7 de dezembro de 1859; 9 de outubro de 1858 e 18 de julho de 1860. 
Artífices], onde moram outros parceiros seus, aí causam às vezes desordens com bebedeiras e rixas". ${ }^{13}$

Os africanos livres compartilhariam os espaços da cidade e do trabalho com escravos e com os indígenas recrutados pelas diretorias parciais. Esta constatação põe em relevo questões importantes sobre as condições precárias da liberdade dos homens livres de cor. A presença de escravos é a chave que permite dimensionar as experiências comuns de diferentes atores e delimitar as fronteiras desta sociedade.

A cidade pela qual Joaquina transitava estava cada vez mais agitada por visitantes, viajantes, naturalistas, comerciantes e trabalhadores de diferentes origens étnicas, sociais e culturais. Foi nesse contexto que Joaquina conheceu o índio José Maria, natural de Ega (Tefé), trabalhador marítimo da escuna de certo França. Ao que tudo indica, José Maria trabalhava para Joaquim José Pinto de França, comerciante estabelecido na vila de Serpa (Itacoatiara). O negócio, situado na Rua do Mar, era abastecido de gêneros vindos do Pará. Também possuía investimentos em Manaus, onde era proprietário de um prédio na Rua da Estrela, paralela à Brasileira. O prédio do patrão de José Maria era bem próximo a casa onde morava Joaquina. Não se pode precisar quando os dois se encontraram, mas o certo é que logo estariam na mira das autoridades policiais. Em 21 de outubro de 1855, às 8 horas da noite, os dois haveriam de fugir... ${ }^{14}$

\section{Escravidão e liberdade: fugas de escravos no Amazonas}

Em julho de 1855, o Amazonas foi atingido por uma violenta epidemia

13 Estrella do Amazonas, 9 de outubro de 1858.

14 Livro de Coletorias das Rendas Provinciais da Vila de Serpa para escrituração dos impostos do interior (1858). As informações sobre os prédios e casas comerciais de França e Braga estão no Estrella do Amazonas, 17, 20 de fevereiro e 27 de janeiro de 1858. A localização foi estimada a partir do mapa Planta dos Bairros de Manáos (1875) do acervo do POLIS. Sobre o contato e a interação entre os grupos indígenas e negros, Stuart Schwartz chama atenção para experiências comuns de suas trajetórias no período colonial (colonização, escravização, restrições ao acesso a terras e exploração da força de trabalho no regime de exportação agrícola); mas acrescenta que estas relações ainda são negligenciadas nos estudos sobre a história das Américas. Ver: Stuart Schwartz, "Tapanhuns, negros da terra e curibocas: causas comuns e confrontos entre negros e indígenas", Afro-Ásia, n. 29/30 (2003), pp.13-40. 
de cólera. A "hedionda enfermidade" atingiu primeiro o Pará e alcançou o Amazonas. $\mathrm{O}$ avanço da epidemia colocou as autoridades em polvorosa, e o presidente Corrêa de Miranda organizou uma verdadeira operação de guerra para conter a doença. Foram meses de intensa atuação médica, policial e religiosa para tratar os enfermos e tranquilizar a população quanto à eficácia das medidas do governo provincial.

Corrêa de Miranda destinou recursos provinciais para atender àqueles que fossem acometidos pela doença na capital e no interior. Em Manaus, ordenou ao médico da Câmara, Antônio Moreira, que indicasse uma casa para servir de enfermaria para tratar os indigentes, e os medicamentos, gratuitos, seriam pagos pelos cofres públicos. Para o fornecimento dos gêneros necessários à dieta dos enfermos, foram contratadas várias casas comerciais, dentre elas a de Antônio Lopes Braga. Para entregar os produtos da dieta elaborada pelos médicos, Joaquina precisaria de "um bilhete declarativo do nome do enfermo, da quantidade, e qualidade do gênero". Havia muita gente a ser atendida e, em tempos de epidemia, o abastecimento da cidade poderia se tornar um sério problema. A casa de Braga estava na boca de todos e a rua Brasileira tornou-se um dos pontos centrais do comércio da cidade. ${ }^{15}$

Encerrado o expediente do dia 21 de outubro de 1855, Joaquina esperou cair a noite, vestiu seu "vestido de chita roxa e camisa de riscadinho cor de rosa" e fugiu. Subiu a rua Brasileira, dobrou para o pequeno Largo da Imperatriz, segurou firme sua lanterna e, em minutos, estava às margens de um pequeno braço do igarapé do Espirito Santo. Lá estava o índio José Maria com sua montaria, a pequena canoa adaptada aos rios amazônicos. Era comum fugir assim. José Maria também era um fugitivo, um desertor. De seus destinos pouco sabemos, até que ela retornasse à cidade quase um ano depois.

A operação de fuga realizada por Joaquina e José Maria foi bastante arriscada. Já ficou claro que estes eram tempos agitados em Manaus. A atuação policial havia aumentado não somente por conta da preocu-

15 Todas as informações sobre as ações de combate ao cólera foram retiradas do Estrella do Amazonas, 21 de julho de 1855 e 18/08/1855. Para uma leitura mais completa, ver Jane Beltrão, Cólera, o flagelo de Belém do Grão-Pará, Belém: MPEG/UFPA, 2004. 
pação com os possíveis infectados, mas também para assegurar que os movimentos de escravos, indígenas, africanos livres e homens pobres no ambiente urbano não se transformassem em desordem generalizada. O frágil controle social dos trabalhadores tornava-se ainda mais difícil quando circulavam pelas cidades alguns exemplos de "criminalidade": os embriagados, desertores, fugitivos, vadios, briguentos, acoutadores de escravos, entre outros "criminosos". ${ }^{16}$

Os dados sobre os registros policiais coletados nos jornais da época são reveladores. No período de 1858 a 1864, o número de prisões apresentou uma evolução percentual significativa: algo em torno de $150 \%$ (tomando como referência os anos de 1858-59, foram registradas 255 prisões, e no triênio 1862-64 o número chegou a 385 presos). A prisão de escravos na cidade já tinha virado alvo da ironia dos "pequenos jornais". O Estrella do Amazonas publicou um "edital burlesco" extraído de um folheto de nome Popular, contendo algumas "normas" para os cidadãos de Manaus. Em seu artigo $4^{\circ}$, o edital dizia o seguinte: "Os negros que divagarem sem bilhete dos senhores serão surrados depois das 10 horas da noite, com açoites de bacalhau em público e raso: pena de multa de 10\$000, se não quiserem levar a dose". Uma leitura mais atenta sugere que os senhores não eram proprietários de escravos, mas de negros, cujo simples divagar noturno deveria ser punido com pública violência. ${ }^{17}$

Não se trata de mera retórica. As autoridades policiais procuravam regular a movimentação dos escravos na cidade, mas também o horário de suas atividades mercantis nos lugares públicos. Na verdade,

${ }^{16}$ Edward Thompson sagrou-se como importante historiador social preocupado com as experiências e os conflitos das camadas trabalhadoras da Inglaterra do século XVIII. Em seus estudos, no que concerne ao direito e ao crime, afirma o caráter complexo da lei como espaço do conflito, de mediação entre os diferentes personagens históricos, analisando as características, a historicidade e lógica própria de seu desenvolvimento no interior da sociedade. Este procedimento analítico garante o mínimo de criticidade sobre o valor moral das motivações e ações dos grupos subalternos, bem como releva certas dimensões da cultura popular, problematizando a noção de crime, no caso do Amazonas, formulada por suas elites dominantes. Ver, entre outros: Edward Thompson, Senhores e caçadores: a origem da lei negra, Rio de Janeiro: Paz e Terra, 1987; Edward Thompson, Costumes em comum: estudos sobre a cultura popular tradicional, São Paulo: Companhia das Letras, 1998, especialmente os capítulos 3, 4, 5.

17 Foram coletados 636 registros de prisões entre 1858-1868. Cumpre lembrar a fragilidade dos dados em função da ausência de exemplares que não permitiu homogeneidade das séries anuais. De qualquer maneira, parece-nos evidente que do final da década de 1850 até o início da seguinte, houve uma intensa atuação policial no Amazonas. 
desde 1859, os vereadores de Manaus estabeleceram a proibição de que escravos continuassem suas vendas nas ruas após o toque de recolher. Em 1861, um edital da polícia da capital lembrava a todos os cidadãos que não era permitido que escravos andassem pelas ruas, depois das 3 horas da manhã, sem bilhete de seus senhores. ${ }^{18}$

Através da repetição via imprensa do regulamento das atividades de comércio de regatão, proibia-se que os escravos sem autorização dos senhores, feitores ou administradores pudessem integrar as embarcações. Os cativos também não poderiam comprar aos mestres de canoas um peixe sequer sem a dita licença escrita. ${ }^{19}$ É importante notar que a lógica de atuação do poder público possuía margens mais amplas. Ao policiar as atividades de escravos no comércio de regatão, buscava-se desarticular as relações e esquemas de comércio clandestino entre as várias comunidades de fugitivos, mocambeiros e quilombolas que abasteciam de forma importante o mercado regional com a produção de seus excedentes econômicos, entre gêneros agrícolas e extrativos. Havia ainda a preocupação que tais contatos pudessem fazer circular informações sobre as transformações políticas nas Américas e no Caribe. Desde as últimas décadas do século XVIII, as autoridades temiam o impacto que poderiam causar as notícias sobre a abolição nas colônias francesas e as lutas de independência nas colônias espanholas, bem como as discussões internacionais em torno da abolição do tráfico e da escravidão. ${ }^{20}$

O controle social dos escravos e trabalhadores negros, tal como em outras cidades do Império, também era caso de polícia em Manaus. ${ }^{21}$

18 Estrella do Amazonas, 13 de julho de 1859 e $1^{\circ}$ de junho de 1861.

19 Estrella do Amazonas, 15 de março de 1856. A lei que regulamenta o comércio de regatão é a n. ${ }^{\circ} 19$ de 25 de novembro de 1853. Coleção das Leis da Província do Amazonas de 1853, Barra do Rio Negro: Typographia de M. S. Ramos. Biblioteca Ramayana de Chevalier do Instituto Histórico e Geográfico do Amazonas.

${ }^{20}$ Flávio dos Santos Gomes, "Em torno dos bumerangues: outras histórias de mocambos na Amazônia Colonial”,Revista da USP, n. 28 (1995), p. 47; Flávio dos Santos Gomes, "No labirinto dos rios, furos e igarapés": camponeses negros, memória e pós-emancipação na Amazônia, c. XIX-XX", História Unisinos, v. 10, n. 3 (2006), p. 282; Eurípedes Funes, "Nasci nas matas, nunca tive senhor", p. 482.

21 Diferentes autores analisaram o controle social da escravaria no ambiente urbano, especialmente em cidades com grande contingente de cativos. A preocupação com a ordem pública constituíase em princípio básico da legislação em diversas cidades do Império. No âmbito historiográfico, o tema suscitou intenso debate sobre os conflitos entre o poder privado e o poder público no 
Os dados indicam que a maioria dos recolhidos à cadeia eram homens com fenótipo associado à escravidão: preto/pardo ou africano (59,9\%; 309 presos). É bem verdade que depois dos africanos livres, os "tapuios" sofriam um pouco mais do que os escravos com a atuação policial (23,2\%; 120 detidos). Quase vinte anos depois, no auge da campanha abolicionista e às vésperas da abolição em Manaus, o jornal Abolicionista do Amazonas denunciava o costume de senhores e autoridades policiais de prender escravos a qualquer pretexto. Segundo o periódico, ainda persistia "a prática abusiva da detenção de escravos na cadeia desta capital, por tempo indefinido, em consequência de simples requisições de seus pretensos senhores". Dessa forma, homens e mulheres negros vivenciaram um processo bastante concreto (e truculento) ao longo de todo período escravista no Amazonas: sobre eles recaía uma suspeição geral e a sistemática precarização de sua liberdade. ${ }^{22}$

controle dos cativos. Ver, entre outros: Leila Mezan Algranti, O feitor ausente: estudo sobre a escravidão urbana no Rio de Janeiro, Petrópolis: Editora Vozes, 1988; José Maia Bezerra Neto, "Mercado, conflitos e controle social. Aspectos da escravidão urbana em Belém (1860-1888), História \& Perspectivas, n. 41 (2009); Marcus J. M. de Carvalho, "Recife: Controles e contraste (1822-1856)", in Maria Angélica Soller \& Maria Izilda Mattos (orgs.), A cidade em debate. Belém, Recife, Rio de Janeiro, São Paulo, Santos, Uberlândia, Curitiba, Porto Alegre, São Paulo: Editora Olho d'água, 1999, pp. 75-108; Sidney Chalhoub, "Medo branco de almas negras: escravos, libertos e republicanos na cidade do Rio", Revista Brasileira de História, v.8, n. 16 (1988), pp. 83-105; Sobre o controle social da escravaria em Salvador no período da permanência da família real, ver: João José Reis, "Notas sobre resistência e controle dos escravos na Bahia, que recebeu a família real em 1808", Revista USP, n. 79 (2008), pp. 106-17; Roberto Guedes Ferreira, "Autonomia escrava e (des)governo senhorial na cidade do Rio de Janeiro da primeira metade do século XIX", in Manolo Florentino (org.), Tráfico, cativeiro e liberdade (Rio de Janeiro, séculos XVII-XIX) (Rio de Janeiro: Civilização Brasileira, 2005), pp. 229-84.

22 Abolicionista do Amazonas, 5 de maio de 1884. Utilizamos os conceitos de suspeição generalizada e precarização da liberdade a partir das reflexões de Sidney Chalhoub. Segundo este autor a historiografia brasileira apresenta algumas lacunas de abordagem no que se refere à avaliação dos contextos históricos específicos e dos mecanismos institucionais que limitavam, e mesmo usurpavam, a liberdade na experiência cotidiana de pretos e pardos livres. Sobretudo nas instituições policiais parecia vigorar o pressuposto de que pessoas com sinais claros de origem africana eram escravos até prova em contrário. No contexto de aumento populacional das cidades e de maior acesso à liberdade, haveria zonas amplas de incerteza social sobre as fronteiras entre escravidão e liberdade que tornavam os livres de cor suspeitos de serem escravos e comprimiam a qualidade da liberdade destes sujeitos históricos. Ver: Sidney Chalhoub, Visões da liberdade, São Paulo: Companhia das Letras, 1990; Sidney Chalhoub, "Costumes senhoriais. Escravização ilegal e precarização da liberdade no Brasil Império", in Elciene Azevedo et al. Trabalhadores na cidade: cotidiano e cultura no Rio de Janeiro e em São Paulo, séculos XIX e XX, Campinas: Editora da Unicamp, 2009; Sidney Chalhoub, "Precariedade estrutural: o problema da liberdade no Brasil escravista (século XIX)", Revista de História Social, n. 19 (2010). 
Diante de tudo que foi dito até aqui, é preciso reconhecer que Joaquina foi, no mínimo, corajosa ao colidir com um conjunto de estratégias das elites locais para coibir os movimentos e práticas de escravos, africanos livres e índios que precisavam ser controlados e subordinados. É importante lembrar que as forças policiais enfrentavam dificuldades para cumprir suas tarefas, fosse pelas deserções constantes dos postos militares, fosse pelas dificuldades de locomoção em uma cidade pouco iluminada, sofrendo várias modificações urbanísticas e entrecortada por matas e igarapés. Seja como for, a constante publicação destas normas revela a própria lógica de atuação do poder público, sistematizada em estratégias de controle de cativos e homens livres, coadunada ao domínio senhorial.

Antônio Braga publicou o anúncio da fuga de Joaquina no jornal quase uma semana depois. Os dias entre a fuga e a publicação do anúncio foram suficientes para que recolhesse as informações precisas da hora, trajes e do "sedutor" da moça. Ao que parece, o capitão também publicou o anúncio em Belém e solicitou àqueles que encontrassem sua escrava "preta crioula, gorda, bem parecida, e muito faladeira" que a entregassem a seu parente Luís Antônio Lopes Braga, na Rua dos Mercadores em Belém.

Joaquina e José Maria eram considerados foragidos da polícia e, como eles, existiam outros mais. Só no período de 1854-1858 existiam anúncios no rastro de 14 escravos fugidos e ao longo da segunda metade do XIX, os dados permitem afirmar que algo em torno de 62 escravos esteve em fuga. Agregando informações dos registros de prisão, notícias sobre captura de escravos fugitivos, o número sobe para 89 fugitivos. As fugas permanecerão como o indicador mais importante da resistência dos escravos até os primeiros anos da década de 1870, quando a quantidade de anúncios nos jornais decresce significativamente no contexto da Lei do Ventre Livre, das ações das sociedades emancipacionistas e do aumento importante da conquista/concessão das cartas de liberdade. ${ }^{23}$

${ }^{23}$ Quase $10 \%$ de toda a escravaria da província escolheu fugir. Estes dados revelam apenas os fugitivos que tiveram seus anúncios publicados nos jornais ou que acabaram capturados. Para fins de comparação, em termos percentuais, São Paulo registrou menos fugitivos que o Amazonas. De acordo com os dados dos jornais paulistas, relativos às três ultimas décadas da escravidão na 
Meses depois de Joaquina, foi a vez de Alexandrina fugir com seu companheiro João Mulato para o rio Negro. Os dois cativos de Antônio Carneiro saíram em plena madrugada da cidade de Belém e subiram o rio Amazonas com destino ao rio Negro. João Mulato conhecia bem os caminhos que seguia porque ali já tinha sido propriedade de outro senhor. Retornar ao rio Negro significava reencontrar antigas amizades (quem sabe, familiares), reatar redes de solidariedade que lhes assegurariam as condições de existência adequadas aos seus anseios. ${ }^{24}$

Anos antes, na cidade de Óbidos, a manhã do dia 11 de janeiro de 1854 não era completa e Raimunda, "24 anos de idade, crioula, bem retinta, um tanto baixa, bem figurada, muito humilde" já estava fugida com seu companheiro José Moisés, "de 26 anos de idade, cafuz bastante fornido do corpo, estatura regular, mal encarado, olhos pequenos, e fundos". Os dois fugiram com a ajuda do forro Antônio Maranhoto, natural do Maranhão que tinha um dos "joelhos fora do lugar, efeito de uma balada quando foi marinheiro de embarcação de guerra". As experiências de escravidão, mar, guerra e liberdade em um só homem foram suficientes para fazer crer ao senhor de Raimunda e José que eles foram "seduzidos" pelo forro Antônio. ${ }^{25}$

Em fevereiro de 1861, a escrava Benedita, "cafuza, natural de Óbidos, com falta de dentes na frente, cabelos cacheados, cheia de corpo, cara risonha" fugiu na companhia do soldado mulato Francisco Lima. Levou uma rede nova, um balaio e um baú de cedro contendo "um par de chinela, um fio de conta de ouro, uma camisa de chita amarela, uma saia de cambraia branca com três folhos e duas camisas brancas". Todas essas

província, a quantidade de fugas em relação ao número de escravos revela um percentual de $0,46 \%$. Por outro lado, em número absolutos o número de fugas registradas em anúncios paulistas é quase cem vezes maior. Ver: Lilia Schwarcz, Retrato em branco e preto. Jornais, escravos e cidadãos em São Paulo no final do século XIX, São Paulo: Companhia das Letras, 1987, p. 138. Com relação às alforrias no Amazonas, Provino Pozza Neto trabalhou com 151 cartas de alforria entre 1850 e 1886 . Afirma que a década de 1870 concentra o maior número de alforrias. Os percentuais são impressionantes: no período de 1860-1870, o aumento é de, pelo menos, $117 \%$. Ver: Provino Pozza Neto, Como se fora de ventre-livre: estudos sobre alforrias no Amazonas imperial, Programa de Iniciação Científica - PIBIC/CNPQ/UFAM, Relatório Final, Agosto/2009, disponível na Biblioteca Setorial do ICHL/Universidade Federal do Amazonas.

24 Estrella do Amazonas, 16 de abril de 1856.

25 Estrella do Amazonas, 21 de fevereiro de 1854. 
peças de roupa serviriam para compor não apenas uma bela indumentária, mas para distingui-la como mulher livre, do pescoço aos pés calçados. ${ }^{26}$

Em abril do mesmo ano, a escrava Maria, "crioula retinta, magra, alta, olhos e beiços grandes" fugiu com Hipólito, "crioulo bem retinto, barbado, falta de dentes na parte superior". Maria e Hipólito fugiram pouco tempo depois do falecimento de seu senhor Antônio Guerra, diretor de índios no rio Madeira. A viúva pedia sua captura e ainda oferecia 100 mil réis de recompensa por cada escravo. O falecimento do senhor sempre foi um momento de tensão para os escravos e suas famílias. A iminência de serem apartados, vendidos para quitar dívidas ou satisfazer herdeiros em disputa foi uma constante ameaça no mundo da escravidão. Para os escravos, a venda podia significar a desintegração dos laços com seus iguais, com seu mundo, sua historicidade, sua identidade social. Maria e Hipólito desejavam um destino diferente. ${ }^{27}$

As mulheres fugiam do cativeiro não só para cuidarem de suas famílias, mas também para tornarem-se senhoras da cidade. Em setembro de 1860, a escrava Lucrézia, "preta retinta, de idade 25 anos", carregou sua camisa de chita, uma saia e se pôs a "andar vagando pelos subúrbios dos Remédios”. O senhor de Lucrézia, Manoel Cruz, possuía três prédios na capital, sendo um prédio e uma casa comercial na rua Brasileira, e outro na rua do Sol, paralela à Brasileira e nas proximidades do Largo da Imperatriz. Dali, Lucrézia podia atravessar a ponte do Espirito-Santo e seguir pela Travessa dos Remédios e, depois de mais uma ponte, tinha um bairro inteiro para circular, mercadejar, lavar suas camisas e saias, viver sobre si, para desespero de seu senhor e das autoridades policiais. ${ }^{28}$

Joaquim Neves, senhor de Benedita com seu bem fornido baú, continuou recorrendo à polícia para recuperá-la dois anos depois da

${ }^{26}$ Estrella do Amazonas, 20 de fevereiro de 1861.

27 Estrella do Amazonas, 6 de abril de 1861. Cristiany M. Rocha, "A morte do senhor e o destino das famílias escravas nas partilhas. Campinas, século XIX”, Revista Brasileira de História, v.26, n. 52 (2006) pp. 177-78. Para melhor compreensão do tema das famílias escravas, ver: Robert W. Slenes, "Lares negros, olhares brancos: histórias da família escrava no século XIX”, Revista Brasileira de História. v. 8, n. 16 (1988), pp. 189-203; Florentino \& Góes, "A paz das senzalas".

28 Estrella do Amazonas, 19 de setembro de 1860. As informações sobre os prédios pertencentes a Manoel Cruz estão no Estrella do Amazonas, 17, 20 de fevereiro e 27 de janeiro de 1858. 
fuga de Óbidos. Benedita estava condenada a cem açoites por sentença em processo de injúria. Andava pela cidade à procura de um comprador e por isso avisava-se aos interessados que não caíssem na "esparrela" de comprar escrava condenada e, "se cair nesse laço, não se queixe ao depois quando a dita sentença for executada". Benedita continuou por mais três meses em fuga, até que foi capturada pelos policiais. Foi no espaço urbano que Benedita buscou redefinir as condições de seu cativeiro buscando outro senhor para comprá-la já que suas repetidas fugas revelam um evidente não quero ao cativeiro de Joaquim Neves. ${ }^{29}$

Histórias de autonomia pelos rios da Amazônia como aquelas de Joaquina e José Maria, de Alexandrina e João Mulato, de Raimunda e José Moyses, de Benedita e Francisco Lima podem ser melhor explicadas (e contadas) se levarmos em consideração outras trajetórias vividas por indivíduos semelhantes daquele mesmo tempo e lugar, colhidas das narrativas de alguns viajantes. Tal procedimento tem sido chamado de analógico, porque permite construir "a narrativa com base em informações possíveis e mesmo prováveis (...) retiradas do contexto” e das histórias assim entrelaçadas. ${ }^{30}$ Sendo assim, Joaquina e José Maria se assemelhariam ao caso da Dona Maria, narrado por Robert Avé-Lallemant quando subia o rio Amazonas no final da década de 1850. A mulher "incomumente robusta, bem parecida, rindo gostosamente" vivia há tempos no Canal de Tajapuru com seu companheiro "mais escuro", sendo naquelas paragens bastante conhecida. Dona Maria era o que se poderia chamar de senhora dos rios, já que remava sozinha

por todos os pequenos igarapés, para vender seus artigos ou trocá-los, e deve ter junto assim uma fortuna. Para maior segurança, leva sempre consigo uma espingarda carregada e um grande facão; conserva-os junto dela na rede, quando dorme. [...] Quase ninguém passa pelo canal do Pará para Manaus que não conheça a célebre amazona Dona Maria, do Canal de Tajapuru, e não mostre grande respeito pela corajosa figura. ${ }^{31}$

${ }^{29}$ O Catechista, 14 de Novembro de 1863; 5 de março de 1864

30 Beatriz Galloti Mamigonian, "José Majojo e Francisco Moçambique, marinheiros das rotas atlânticas: notas sobre a reconstituição de trajetórias da era da abolição", Topoi, v.11, n. 20 (2010), pp. 75-91.

31 Robert Avé-Lallemant, No rio Amazonas (1859), Belo Horizonte/São Paulo: Editora Itatiaia/ Editora da Universidade de São Paulo, 1980, p.65. 
Seguindo viagem também pelo rio Amazonas, Paul Marcoy encontrou "dois velhos de pele escura" que viviam há tempos refugiados no interior da floresta. Pelo que conta o viajante, o casal de "velhos mestiços" possuía um serviçal, um "índio tapuia", que lhes ajudava no cultivo de uma pequena plantação de alimentos cujos excedentes eram trocados por "sal, algodão, veneno para a caça e implementos de pesca com os moradores de Ega e Caiçara". Em noites anteriores, Marcoy havia se deparado com "um casebre" rodeado por uma pequena varanda que servia de horta, habitada por "três desertores (...) que aqui viviam em paz e segurança com suas mulheres pardas de narizes achatados". Ao seguir seu rumo, Paul Marcoy ficou muito agradecido ao receber "alguns abacaxis colhidos na sua horta" para não revelar às autoridades o paradeiro dos "bons camaradas". ${ }^{32}$

As fugas de Joaquina, Raimunda, Alexandrina, Benedita, Lucrézia revelam algo mais que a recusa ao cativeiro. A maioria destas histórias manifesta uma preocupação comum: o estabelecimento de laços familiares. Isto pode indicar que a autonomia para formação dos lares, criação dos filhos, escolha de parceiros para compartilhar a vida esteve no âmago daquilo que as mulheres escravizadas entendiam como liberdade. Por outro lado, o viver sobre si no espaço urbano aponta para o anseio de maior autonomia nas tarefas domésticas, nas atividades de ganho nas ruas, nas tabernas, vendas e casas de comércio.

Em 1870, corria nos jornais um apelo para que se tomassem as providências contra um constante ajuntamento de escravos vendedores nos arredores da rua Brasileira. Eram acusados de atentar contra a "honra da pública moralidade". Segundo o jornal, em toda e qualquer hora,

juntam-se nas rampas (...), nas pontes e em outros lugares, troças de vendedeiras e outras desocupadas que de envolta com marinheiros, escravos, e etc. dão bem tristes exemplos de moral. As palavras obscenas são comuns nas bocas dessas assembléias e ouvem-nas todos os que por necessidade ou recreio passam nesses lugares. ${ }^{33}$

\footnotetext{
32 Paul Marcoy, Viagem pelo rio Amazonas, Manaus: Editora da Universidade Federal do Amazonas, 2006. Respectivamente, os casos podem ser encontrados nas páginas 119 e 107.

33 O Catechista, 16 de julho de 1870.
} 
A animada conversa revela que alugar serviços para atividades domésticas, obras públicas, sair às ruas como "negros de ganho" era uma estratégia disponível e sabidamente eficaz para acumular algum pecúlio, legalizado pela lei de 28 de setembro de 1871. Juntando seu pecúlio, escravos e escravas conseguiam maior autonomia para gerir seus próprios destinos e, no limite, comprar a própria carta de liberdade. E assim foi feito pelas escravas no Amazonas.

A maioria das alforrias concedidas na província foi onerosa $(61 \%$; 75 cartas), ou seja, resultado do penoso processo de trabalho e acumulação de pecúlio dos escravos. Das escravas, melhor dizendo, já que mais da metade dos alforriados são mulheres (56\%; 95). Cabe lembrar que o aumento da concessão de cartas de liberdade coincidiu com o movimento ascendente de obtenção da alforria por mulheres nas décadas de 1860-70. Mais do que isso, o aumento da concessão dessas cartas não estava necessariamente subordinado à cooperação humanitária do senhor. De acordo com Pozza Neto,

No momento em que leis favoreciam a emancipação indenizando os senhores com dinheiro dos cofres públicos, além das comissões civis que se organizavam para arrecadar fundos para este fim, muitos senhores preferiam se aproveitar desta oportunidade e lucrar com a venda da liberdade de um escravo seu. ${ }^{34}$

Joaquina reaparece, afinal. Retornou à capital quase um ano depois, se é que ela esteve realmente fora da cidade este tempo todo. Carregava consigo, em moeda corrente do Império, a quantia de um conto de réis. Caminhou novamente pela rua Brasileira e procurou pelo seu senhor. Joaquina voltou para comprar sua carta de liberdade. Antônio Lopes Braga, negociante pela vida tornado experiente, hesitou; declarou ser a quantia insuficiente "para o seu valor na atualidade, e principalmente pela falta de quem me sirva”. E tinha lá as suas razões.

Dois parecem ter sido os motivos. Primeiro porque um dos efeitos da abolição definitiva do tráfico ilegal foi a acentuada valorização do preço dos escravos. O aumento do preço do braço cativo era o

34 Provino Pozza Neto, "Como se fora", p. 37. 
corolário da expansão das atividades cafeeiras no Sudeste brasileiro. E ao que parece, as elites senhoriais do Pará e do Amazonas não estavam tão interessadas em participar do tráfico interprovincial e sangrar os suas escravarias em favor dos fazendeiros do Nordeste e Sudeste brasileiro. ${ }^{35} \mathrm{Em}$ termos gerais, a regra parece ter sido manter o contingente escravo. O segundo motivo se distancia um pouco das lógicas de mercado e aciona as relações de servidão baseadas na obediência e fidelidade sob as quais Joaquina estava ligada ao seu senhor. Por outro lado, não era incomum a estratégia de ampliação da escravaria através da reprodução natural. ${ }^{36}$ Os futuros filhos de Joaquina poderiam multiplicar, sem maiores custos, o lote de trabalhadores e sanar "a falta de quem me sirva" do capitão Braga.

A negociação foi tensa, como era de se esperar. Pelo que se sabe, nenhuma das cartas de alforria concedidas na década de 1850 foi gratuita ou dispensou algum tipo de "condição". A alta dos preços restringia o acesso à alforria e limitava a constituição do capital adequado para levar à efeito a negociação. Aliás, o costume dos escravos de acumularem pecúlio só seria assegurado pela formalidade da lei em 1871 com a Lei do Ventre Livre. A liberdade de dispor de si, portanto, era conquista dificílima, mas não impossível.

E para Joaquina a compra da alforria parecia ser condição fundamental naquele momento. Por vários motivos. O incremento do tráfico interno tornou ainda mais precária não só a vida dos escravos, mas também dos libertos. A prática intensa de sequestro de negros livres e libertos; a atuação de quadrilhas e redes de "sedução" para exportação de

35 José Maia Bezerra Neto, "Escravidão e crescimento econômico no Pará (1850-1888)", in Aldrin Moura de Figueiredo \& Moema de Bacellar (orgs.), Tesouros da memória. História e patrimônio no Grão-Pará (Belém: Ministério da Fazenda - Gerência Regional de Administração no Pará/Museu de Arte de Belém, 2009). Estudos de Manolo Florentino sobre alforrias na cidade do Rio de Janeiro entre 1789 e 1831 mostram que "após o fim do tráfico com a África, o valor de um escravo com estas características triplicou em relação à década de 1840, atingindo o pico (cerca de 1:500\$000 réis) nos anos 60". Ver: Manolo Florentino, "Sobre minas, crioulos e a liberdade costumeira no Rio de Janeiro, 1789-1871" in Manolo Florentino (org.), Tráfico, cativeiro e liberdade. Ri ode Janeiro, séculos XVII-XIX (Rio de Janeiro: Civilização Brasileira, 2005), p. 340.

${ }^{36}$ Carlos de Almeida Prado Bacellar, "A Escravidão miúda em São Paulo colonial", in Maria Beatriz Nizza da Silva (org.), Brasil: Colonização e Escravidão (Rio de Janeiro: Nova Fronteira, 2000), p. 243. 
escravos em direção ao Sudeste cafeeiro; ${ }^{37}$ bem como a intensa atuação da polícia no controle da população negra na província tornavam a vida em liberdade deveras insegura e precária. Por outro lado, a libertação via alforria condicional também transformava o futuro num horizonte de incertezas, pois vulnerável à re-escravização. ${ }^{38}$ Todos esses elementos devem ter sido analisados por Joaquina. Dessa forma, a vontade de comprar a alforria revela uma estratégia bastante perspicaz de sua parte: defender a liberdade com melhores condições políticas e conquistar maior autonomia em relação ao ex-senhor.

Não se pode precisar o quanto Braga se convenceu ou foi convencido. Na letra da lei, Antônio Lopes Braga disse que assinava "sem constrangimento algum", menos pela quantia que lhe foi apresentada por Joaquina do que "por ser este um ato de beneficência, e em atenção aos serviços que me prestou durante o tempo de servidão: em vista das quais lhe dou plena liberdade". Se o comerciante ficou (ou não) com o dinheiro, nada se registrou... ${ }^{39}$

\section{Joaquina, mulher livre: conclusões sobre outras histórias que ainda virão...}

A história de Joaquina nos chegou através de fragmentos. A bem da verdade, a vida que acabamos de reconstituir só foi possível na encruzilhada de outras histórias. Tais evidências só puderam fazer sentido em suas relações não só com outros fragmentos, mas também quando lidas em seus respectivos contextos sociais, políticos, econômicos e culturais.

Joaquina nasceu e cresceu em uma sociedade bastante empobrecida cuja lógica de reprodução se assentava na sistemática exclusão e

37 Sidney Chalhoub, "Precariedade estrutural", pp. 41-9. Ver também: Hebe Mattos, "Raça e cidadania no crepúsculo da modernidade escravista no Brasil", in Keila Grinberg \& Ricardo Salles (orgs.), O Brasil Imperial, volume III (1870-1889) (Rio de Janeiro: Civilização Brasileira, 2009), p. 21.

38 Estudos de Keila Grinberg demonstram que os escravos que conquistavam a liberdade através de uma alforria condicional estavam mais vulneráveis à possibilidade de revogação da alforria por motivos de ingratidão. Ver: Keila Grinberg, "Senhores sem escravos: a propósito das ações de escravidão no Brasil Imperial”, Revista Almanack Braziliense, n. 6 (2007).

39 Carta de liberdade publicada no Estrella do Amazonas, 28 de junho de 1856. 
hierarquização de uma parte significativa de sua população. ${ }^{40}$ As conturbações políticas e sociais das primeiras décadas do século XIX acentuaram a retração e a desarticulação econômica. Joaquina viveu no estrato mais baixo desta estrutura e a sua simples presença ajudava a reproduzir relações de subordinação e exclusão. A reorganização política e administrativa no extremo norte do Estado imperial brasileiro, no período pós-Cabanagem, permitiu a pessoas, como o capitão Braga, espaço nos locais mais importantes da política local. Suas atividades como militar, comerciante e vereador reproduziam a sua presença no jogo político. A posse de escravos era fundamental nesse processo. A propriedade de uma mercadoria tão cara lhe habilitava no mercado, conferia status social e ainda agregava renda política.

Joaquina fugiu em um momento muito conturbado. Muitos escravos fariam o mesmo. Aproveitariam uma cidade agitada com as modificações no espaço urbano, com o temor das epidemias, com a maior circulação de vapores, canoas e trabalhadores e com o aumento das fugas escravas e enfrentariam o recrudescimento da atuação policial. Enfim, em pleno processo de organização política e econômica da província é que Joaquina percebe os seus interesses profundamente distantes dos de seu senhor. $\mathrm{O}$ amor de José Maria e a possibilidade de uma nova vida são prova disso.

Mesmo com histórias distintas, a maioria das fugas de mulheres escravizadas no Amazonas guardava um sentido comum: o estreitamento de laços familiares. A conquista de um espaço de autonomia para construir estes laços é o que parece caracterizar a noção de liberdade destas mulheres: cuidar de seus filhos, permanecer junto de companheiros e parentes, fugir da separação pelas vendas, entre outras. Mas não só isso.

${ }^{40}$ Se compararmos as as faixas de fortunas de Manaus com as do Rio de Janeiro, verificamos que toda a fortuna líquida registrada para Manaus no período de 1840-1880 é apenas três vezes maior do que uma única fortuna encontrada no Rio de Janeiro. É importante não esquecer os componentes extraeconômicos que asseguraram a reprodução da hierarquia social através de uma intrincada rede de relações pessoais que garantiam a acumulação de riquezas e a própria atuação no circuito mercantil. Ver: Patrícia M. Sampaio, "Nas teias da fortuna: acumulação mercantil e escravidão em Manaus, século XIX", p. 140. Sobre acumulação de riquezas no Rio de Janeiro ver, entre outros, João Luís Fragoso, Homens de grossa aventura: acumulação e hierarquia na praça mercantil do Rio de Janeiro (1790-1830), Rio de Janeiro: Arquivo Nacional, 1992. 
Circular e viver sobre si no espaço urbano também motivou muitas escravas, vendendo quitutes e doces, lavando, cozendo, engomando para juntar pecúlio. Muitas foram as estratégias para se manterem em fuga ou conquistar a carta de liberdade como Joaquina.

A proibição definitiva do tráfico de escravos em 1850, resultado dos embates políticos entre as elites imperiais e da intensa atuação internacional da Inglaterra pelo fim da escravidão, bem como a aprovação, no mesmo período, da Lei de Terras sinalizavam reformas para a emancipação. Depois da Lei do Ventre Livre, esse processo de inflexão se acentua e a legitimidade da escravidão sofre abalos profundos. ${ }^{41}$ Cabe perguntar qual a importância das estratégias de vida de homens e mulheres escravizados nesse processo.

Sobre suas histórias como mulheres livres pouco (ou quase nada) se sabe e este é um passado que precisa ser investigado. O que é possível dizer aqui com alguma certeza é que o processo de resistência ao cativeiro, durante as décadas de 1850-1860, percebe nas fugas o seu melhor instrumento. A partir da década de 1870, de modo estratégico, escravas e escravos passam a combinar fugas (menos frequentes, é verdade) e alforrias para transformar as suas condições de vida e, no limite, desintegrar politicamente o cativeiro.

Na tentativa de proteger seus laços familiares contra a venda de seus membros; conquistando autonomia para dispor de si nos espaços urbanos; mercadejando, acumulando pecúlio, fazendo circular informações e prestando auxílio aos desertores e fugitivos; as ações de mulheres como Benedita, Alexandrina, Raimunda, Maria, Lucrézia e Joaquina são importantes indícios para a compreensão do processo de extinção da escravidão no Amazonas.

Texto recebido em 10/8/2011 e aprovado em 2/11/2011

${ }^{41}$ Hebe Mattos. "Raça e cidadania no crepúsculo da modernidade escravista no Brasil", pp. 19-23. 


\title{
Resumo
}

O presente texto procura retratar a vida de Joaquina que viveu como escrava no Amazonas do século XIX. Tomando-a como fio condutor da análise, busca discutir um amplo panorama das intrincadas relações sociais, de poder, econômicas e culturais vivenciadas pelos escravos que, localizados nas camadas mais baixas de uma estrutura desigual e excludente, fugiam, redefiniam o cativeiro e transformavam as suas condições de vida. Também reflete sobre o protagonismo das mulheres escravizadas no espaço urbano, suas estratégias de conquista de alforria e os significados de liberdade para as fugitivas, e como estes protagonismo foi importante para o processo de desintegração do cativeiro.

Palavras-chave: escravidão - fugas - Amazônia - resistência escrava.

\begin{abstract}
This paper seeks to bring to light the life of Joaquina, a woman who was a slave in the Amazon region during the $19^{\text {th }}$ century, and through this lens to give a broad overview of an intricate web of social, economic and cultural power in which slaves were bound. Slaves were the least privileged class social of social actors and flight from captivity was one of the options they could resort to in attempting to transform their situations. The paper also reflects on the role of women enslaved in urban environments and their strategies for obtaining letters of manumission, as well as the meanings of freedom and its importance in the disintegration of slavery as a social institution.
\end{abstract}

Keywords: slavery - runaway slaves - Amazon - slavery resistance 